\title{
ВОЗМОЖНОСТИ \\ ЛИНГВИСТИЧЕСКОГО АНАЛИЗА ИНОЯЗЫЧНЫХ ВКРАПЛЕНИЙ ПОЛЬСКОГО ПРОИСХОЖДЕНИЯ В ЛЕКСИКЕ РУССКОГО ЯЗЫКА
}

\section{ЛУКАШ ПЛЕСНИК}

\section{POSSIBILITIES OF LINGUISTIC ANALYSIS OF FOREIGN LANGUAGE INCLUSIONS OF POLISH ORIGIN IN THE VOCABULARY OF THE RUSSIAN LANGUAGE}

ABSTRACT The article is devoted to the problem of foreign language inclusions of Polish origin in the vocabulary of the Russian language. The main attention is paid to three linguistic analyzes (etymological, semantic and stylistic), which are presented on the basis of the created database of language data. Etymological analysis examines the inclusions of Polish origin according to their belonging to the Polish language as a source or intermediate language, semantic analysis pays attention to the distribution of Polish-language inclusions according to lexical and semantic groups, stylistic analysis classifies the inclusions of Polish origin according to their speech style.

KEY WORDS foreign language inclusion, barbarism, polonism, intermediary language, source language, etymological analysis, semantic analysis, stylistic analysis, Polish language, Russian language

CONTACT Ostravská univerzita; lukas.plesnik@osu.cz 


\section{$1 /$ ВВЕДЕНИЕ}

Вопрос об иноязычных вкраплениях в лексической системе языка-реципиента тесно связан с проблематикой процесса заимствования, который можно считать одним из результатов взаимодействия сталкивающихся друг с другом языков. Политические, экономические, культурные и, не в последнюю очередь, военные связи в истории русско-польских отношений в значительной мере повлияли на появление иноязычных вкраплений польского происхождения в лексике русского языка. Хотя польскоязычные заимствования по своему количеству не могут уступать заимствованиям из классических языков (древнегреческий и латинский) или других западноевропейских языков (немецкий, французский, английский), их число достойно внимания и заслуживает собственного лингвистического анализа.

Иноязычные вкрапления, близки по своей формально-структурной характеристике варваризмам ${ }^{1}$, представляют собой иноязычные элементы, встречающиеся в языке-реципиенте без морфологических или синтетических изменений. Энщиклопедчческий словарь-справочник лингвистических терминов и понятий. Русский язык под общ. ред. А. Н. Тихонова и Р. И. Хашимова толкует иноязычное вкрапление, ссылаясь непосредственно на понятие трансплантация. Процесс трансплантации определяется как «способ заимствования иноязычного слова или выражения при полном сохранении его графического облика» (Тихонов - Хашимов 2008: 550, 571). Следует отметить, что данный способ применяется, прежде всего, при включении лексических единиц из языков с тождественными алфавитами, однако его признаки можно наблюдать также в случае несходных графических систем (латиница / кириллица). Трансплантация исключает возможность графического варьирования, однако, в этом случае неизбежно возникают произносительные варианты, так как правила чтения в языке-источнике и языке-реципиенте отличаются друг от друга. Если сосредоточиться на иноязычные вкрапления польского происхождения, то можно для их номинации использовать, в общем смысле слова, применяемый термин полонизм, представляющий собой заимствованное слово из польского языка. ${ }^{2}$

Как мы уже отметили, несмотря на то, что количество польскоязычных вкраплений в словарном составе русского языка сравнительно невелико, все-таки такого рода лексические единицы заслуживают особого внимания. Ниже представлены три главных анализа, т.е. исследуются этимологический, семантический и стилистический аспекты полонизмов в русском языке. База языковых данных, на чьей основе проведены

1 Вопрос о варваризмах, т.е. не полностью освоенных или совсем не освоенных заимствованных словах, довольно сложен. Подробное изложение термину варваризм дает Словарь лингвистических терминов О. С. Ахмановой, указывающий три разных определения: 1. «слово, образованное 〈неправильно〉, т.е. не в соответствии с «правилами〉 (или моделями) словообразования, словоизменения или сочетания слов, действующими в данном языке и/или являющееся исторически (этимологически) необоснованным»; 2. «иноязычное слово, употребляемое при описании чужеземных обычаев, особенностей жизни и быта (реалий) для придания изложению местного колорита»; 3. «иностранное слово, не получившее прав гражданства в общем языке и бытующее лишь в некоторых специфических социальных его разновидностях» (Ахманова 1966 [2016]: 70).

2 Более подробному изложению основных терминов теоретической основы полонизмов посвящена статья Иноязычные вкрапления польского происхождения в лексике русского языка (общие положения). Ср. Плесник 2020: 67-75. 
определенные анализы, базируется на нормативных словарях современного русского и польского языков. Главнейшим источником послужил Большой этимологический словарь русского языка М. В. Климовой (2016), из которого были выписаны все иноязычные вкрапления польского происхождения. Этимологический анализ опирается также на Этимологический словарь современного русского языка А. К. Шапошникова (2010), Историко-этимологический словарь современного русского языка П. Я. Черных (2009) и Этимологический словарь русского языка М. Фасмера (1950-1958). Семантический и стилистический анализы основаны на материале толковых словарей русского и польского языков, а именно Толкового словаря русского языка С. И. Ожегова и Н. Ю. Шведовой (2017) и Словаря польского языка (Słownik języka polskiego) Э. Собол (2009). Нами собранная база языковых данных в общем насчитывает 240 вкраплений польского происхождения.

\section{2 / ЭТИМОЛОГИЧЕСКИЙ АНАЛИЗ}

Этимологический анализ польскоязычных вкраплений осуществлен посредством двух основополагающих подходов. Первый подход - определение группы полонизмов, относящихся реально к польскому языку как языку-источнику, второй - определение группы полонизмов, относящихся к польскому языку как языку-посреднику. В общем можно констатировать, что для 36 полонизмов польский язык является непосредственно языком-источником, а в случае 204 полонизмов польский язык выступает в качестве языка-посредника. В нашем анализе мы отдельно рассматриваем два вкрапления польского происхождения (см. ниже лексемы аист и баранка), этимология которых проблематична.

Польский язык воспринимается в качестве языка-источника на примере вкраплений белизна, вензель, доскональный, забияка, завзятый, заядлый, зразы, клянчить, мазурка, малевать, мещанин, пан, паршивый, плохой, повидло, подлый, поединок, позволить, полковник, потрафбить, разруха, рожа, сейм, скромный, смак, уважать, укроп, ффигли-мигли, фбиляяр, хоругвь, хорунжий, шинкарь, шмат, шматок, шпенек, шумовка. Среди данной группы полонизмов встречаются лексические единицы, относящиеся, главным образом, к существительным (ср. вензель, зразы, фбигляр и др.), но также к глаголам (ср. позволить, потрафбить, уважать и др.) и прилагательным (ср. доскональныци, подлый, скромный и др.).

Сравнительно чаще польский язык выполняет роль языка-посредника. В таком случае этимологический путь определенного вкрапления обусловлен принадлежностью к первоначальному языку-источнику. К числу такого рода первоначальных языков-источников можно отнести в первую очередь классические языки (латынь и древнегреческий язык), затем немецкий, французский, итальянский, арабский, венгерский, чешский языки, идиш, голландский язык или группу тюркских языков. Классификацию вкраплений польского происхождения по принадлежности к польскому языку как языку-источнику / языку-посреднику иллюстрирует диаграмма № 1 (см. ниже).

Господствующей группой первоначальных языков-источников, без сомнений, являются классические языки. По количеству преобладают первоначальные заимствования излатинскогоязыка,первоначальныхзаимствованийиздревнегреческого языка почти в четыре раза меньше. К латинскому языку как первоначальному источнику 
заимствования относятся 94 вкрапления (ср. администратор [< польск. administrator <нем. Administrator<лаm. administrator], бутылка [< польск. butelka < франи. bouteille <лаm. buticula], карета [< польск. kareta < ит. carretta < лат. carrus], композитор [< польск. koтpozytor < ит. compositore < лат. compositor], линия [< польск. linia <нем. Linie <лат. linea], оказия [< польск. okazja < лат. oсcasio], пориия [< польск. porcja < лат. portio], религия [< польск. religia < лат. religio], фрукт [< польск. frukt<лат. fructus], шалфей [< польск. szalwia < нем. Salveie < ит. salvia<лam. salvia] и др.), к древнегреческому языку - 25 вкраплений (ср. агония [< польск. agonia < др.-греч. $\dot{\alpha} \gamma \omega \nu i \alpha$ ], гитара [< польск. gitara< <сn. guitarra < др.-греч. $\chi \imath \dot{\alpha} \rho \alpha$ ], каштан

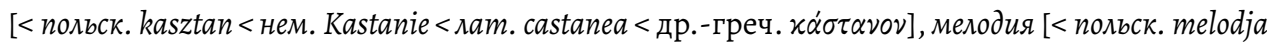

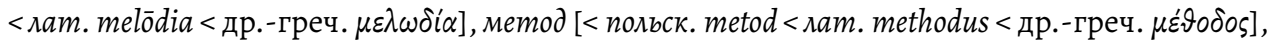

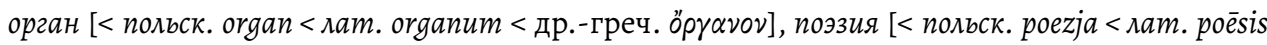
< др.-греч. тоїбгs], проблема [< польск. problema < нем. Problema < лат. problēma < др.-греч.

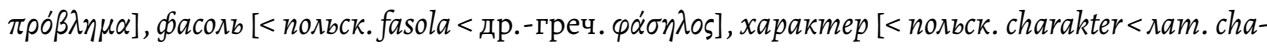
racter < др.-греч. $\chi \alpha \rho \alpha x \tau \eta \dot{\rho}]$ и др.). Общеизвестно, что в рамках этимологического пути, в котором первоначальным языком-источником является древнегреческий язык, часто положение вторичного языка-источника (посреднического языка-источника) выполняет латынь (ср. вкрапления типа академик, меланхолия, мелодия, метод, музыка, орган, поэзия, характер, холера, иирюльник и др.). На основе отмеченой выше господствующей роли латыни и древнегреческого языка как первоначальных языков-источников можно подчеркнуть, что греко-латинская основа многочисленных вкраплений польского происхождения в русском языке доказывает значительную активность классических языков в процессе интернационализации словарного состава.

К числу достаточно распространенного языка-источника следует отнести также немецкий язык. Полонизмы, ссылающиеся на первоначальный язык-источник в форме лексической единицы немецкого языка, образуют 47 вкраплений (ср. бант [< польск. bant $<$ нем. Band], бунт [< польск. bunt<нем. Bund], валторна [< польск. waltornia <нем. Waldhorn], карлик [< польск. karlik < нем. Karal], отвага [< польск. odwaga <нем. Wagen], паковать [< польск. pakować < нем. Packen], рама [< польск. rama < нем. Rahmen], pыцарь [< польск. rycerz<нем. Ritter], ģартук [< польск. fartuch < нем. Vortuch], шлифбовать [< польск. szlifować< нем. Slifen] и др.). В преобладающем большинстве случаев полонизмы, относящиеся к основе немецкого языка, представляют собой заимствования эпохи правления русского царя Петра I (ср. заимствования XVII и XVIII вв. типа бунm, вахта, вербовать, рынок, рыцарь [XVII в.], минога, отвага, ротмистр, рычаг, столяр [XVIII в.] и др.).

Сравнительно меньшую группу полонизмов образуют выражения, относящиеся этимологически к французскому и итальянскому языкам. Французский язык представляет собой первоначальный язык-источник 13 польскоязычных вкраплений (ср. булка [< польск. butka < франц. boule], манера [< польск. maniera < франи. manière], panopm [< польск. raport < франц. rapport], регламент [< польск. reglament < фрранц. règlement], ффармазон [< польск. farmazon < ффранц. franc-macon] и др.), итальянский язык 8 вкраплений польского происхождения (ср. бастовать [< польск. bastować < um. bastare], баталия [< польск. batalja < нем. Bataille < um. battaglia], гвардия [< польск. gwardja < ит. guardia], каналья [< польск. kanalia < франц. canaille < um. canaglia], капрал [< польск. kapral $<$ фррани. caporal< um. caporale] и др.). 
Остальные языки-посредники, встречающиеся в нами собранной базе языковых данных, занимают относительно вкраплениям польского происхождения в русском языке лишь маргинальное положение. К ним относятся арабский, венгерский, чешский языки, идиш, голландский язык и группа тюркских языков. Арабский язык является первоначальным языком-источником четырех полонизмов (ср. атлас [< польск. attas < нем. Atlas < араб. ațlas], лютня [< польск. lutnia < нем. Lûte < араб. al-'Süd], иифровой [< польск. cyfrowy < нем. Ziffer < араб. sifr], юбка [< польск. јира < араб. јиbba]), венгерский язык - трех полонизмов (ср. бекеша [< польск. bekiesza < венг. bekes], гусар [< польск. husar < венг. huszár], шеренга [< польск. szereg < венг. sereg]), чешский язык - двух полонизмов

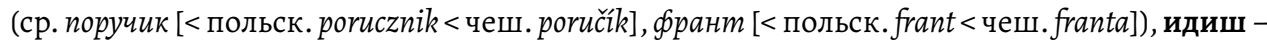
двух полонизмов (ср. фбанаберия [< польск. fanaberia < идиш faine и berje], шабаш [< польск. szabas < идиш Schabbes]), голландский язык - одного полонизма (ср. вахмистр [< польск. wachmistrz < голл. wachtmeester]). К группе тюркских языков как языке-основе относятся всего 3 польскоязычных вкрапления (ср. козырь [< польск. kozera < тюрк. (mam.) kuzyr], темляк [< польск. temblak< тюрк. (mam.) tämlik], улан [< польск. ułan <mюрк. (азерб.) oylan]). Классификацию вкраплений польского происхождения по принадлежности к языку-посреднику иллюстрирует диаграмма № 2 (см. ниже).

На основе указанных выше примеров следует отметить, что в процессе этимологического определения конечного польскоязычного вкрапления принимают участие не только лексические единицы первоначальных языков-источников, однако помимо польского языка как языка-посредника выступают в той же самой функции также другие языки, оказывающие посредничество в формировании целевого полонизма. Итак, относительно количества могут встречаться или один (ср. peecmp < польск. rejestr < лат. regestum и др.), или два (ср. тракт < польск. trakt<нем. Trakt<лат. tractus и др.), или

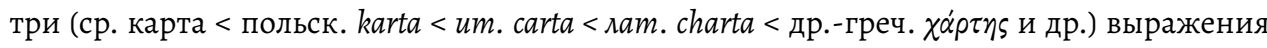
определенных языков-посредников.

В нами собранной базе языковых данных имеются с точки зрения этимологического укрепления также выражения, этимология которых проблематична. К ним можно отнести, например, лексические единицы аист и баранка. Этимологический словарь русского языка М. Фасмера связывает лексему аист с польским выражением hajster, однако Этимологический словарь современного русского языка А. К. Шапошникова считает языком-основой немецкое диалектное слово Hejster. Лексема баранка связана относительно первоначального языка-источника в Большом этимологическом словаре русского языка М.В. Климовой или с польским языком (< польск. obarzanek), или с белорусским языком (< блр. абаранак). Однако, Этимологический словарь современного русского языка А.К. Шапошникова указывает также на возможность собственно русского слова, т.е. собственно русского новообразования с суффиксом -ка (-ъка) от унаследованного из прасл. языка *баранъ.

\section{3 / СЕМАНТИЧЕСКИЙ АНАЛИЗ}

Семантический анализ опирается на 10 ключевых лексико-семантических областей, сгруппированных на основе близкого тематического сходства. Вкрапления польского происхождения в русском языке распределены в следующие тематические области: 
термины экономики и административного аппарата, военные термины, термины гастрономии, культуры, моды, флоры и фауны, медицинские термины, термины науки и транспортного сообщения, ремесленные термины и термины игры. Полонизмы, не принадлежащие к тематически разграниченным выше семантическим группам, включены в самостоятельную группу остальных выражений.

К самым многочисленным лексико-семантическим группам относятся термины из области экономики и административного аппарата и термины военного дела. Термины экономики и административного аппарата образуют 41 полонизм. К ним принадлежат чаще всего лексические единицы греко-латинской основы (ср. аккредитовать, канцелярия, компания, литер, магнат, монета, почта, реестр, таблииа, фабриковать и др.). По количеству входящих выражений почти сходна тематическая группа, обозначающая военные термины. Они образуют 39 полонизмов (ср. бастовать, вербовать, капрал, курок, рапорт, таран, темляк, улан, хоругвь, штурмовать и др.). С точки зрения первоначального языка-источника встречаются разнообразные языки, в том числе немецкий, французский или итальянский языки.

В диапазоне от 20 до 10 вкраплений польского происхождения можно перечислить пять лексико-семантический групп. Термины гастрономии составляют группу, насчитывающую 17 полонизмов (ср. баранка, булка, буханка, зразы, индюк, кухня, повидло, пориия, смак, укроп и др.). Сходным количеством представлена также группа терминов культуры, в состав которой входят польскоязычные вкрапления из области музыки, танца или литературы (ср. автор, валторна, вензель, гитара, композитор, лютня, мазурка, музыкант, танец, иимбалы и др.). Термины моды образованы 12 полонизмами (ср. атлас, бант, бекеша, замша, кант, куртка, фбалда, фљартук, шпилька, юбка и др.), тем же количеством образована также лексико-семантическая группа терминов флоры и фауны (cp. aucm, каштан, кролик, лавр, лилия, петрушка, фасоль, фиалка, цикорий, шалфбей и др.). Свыше десятью лексическими единицами представлена также группа медицинских терминов, их общее количество - 11 полонизмов (ср. комплекция, медищина, мускул, орган, паралич, рожа, холера, иинга, шиенек, шрам и др.).

Сравнительно небольшие лексико-семантические группы можно выделить на примере вкраплений польского происхождения трех тематических областей. Термины науки и транспортного сообщения образованы 9 полонизмами (ср. бричка, карета, курьер, механик, станция и др.), ремесленные термины представляют собой 6 полонизмов (рычаг, столяр , шлифовать, шпаклевать, шпонка и др.), термины игры - сходно 6 полонизмов (карта, луза, тасовать, туз, фбант и др.).

В сторону классификации польскоязычных вкраплений мы оставили довольно большую группу полонизмов, принадлежность к намеченным выше лексико-семантическим группам или неоднозначна, или по тематике с ними не полностью совпадает. Группа остальных выражений данного типа образует всего 70 полонизмов, с тематической точки зрения - это самые разнообразные лексические единицы польского происхождения (ср. амбиция, белизна, вахта, забияка, завзятый, заядлый, манера, меланхолия, метод, объект, оказия, опека, потрафбить, религия, скромный, термин, уважать, фортель, шпаргал$\kappa a$, шулер и др.). На основе указанных выше примеров можно отметить, что многие понятия данной группы - отвлеченные выражения (ср. амбищия, белизна, скромный и др.), 
поэтому их точная тематическая определенность неоднозначна. Некоторые выражения также принято считать общими терминами греко-латинской основы (ср. метод, объeкm, термин и др.). Классификацию вкраплений польского происхождения по лексико-семантической принадлежности иллюстрирует диаграмма № 3 (см. ниже).

\section{4 / СТИЛИСТИЧЕСКИЙ АНАЛИЗ}

Стилистический анализ сделан по принципу принадлежности вкрапления польского происхождения к определенному стилю речи. На основе проведенного нами анализа можно распределить собранный лексический материал на шесть основных стилистических групп, т.е. мы выделили группы полонизмов, относящихся к нейтральному, разговорному, устаревшему, просторечному, книжному и специальному стилям речи.

Среди отмеченных стилистических уровней русского языка однозначно преобладают польскоязычные вкрапления, относящиеся к нейтральной лексике. Они насчитывают всего 201 лексическую единицу (ср. амбиция, башня, бутылка, вахта, замок, канцелярия, композитор, лектор, мелодия, объект, орган, пориия, реестр, станция, термин, фьакт, холера, шалфей, шрам, ярмарка и др.).

Относительно многочисленными можно считать полонизмы, принадлежащие к разговорному и устаревшему пласту лексики русского языка. Польскоязычные вкрапления разговорной лексики составляют группу, состоящую из 16 выражений (ср. забия-

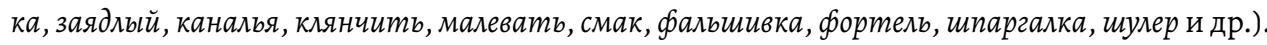
Полонизмы, относящиеся к устаревшей лексике насчитывают 15 лексических единиц (ср. баталия, оказия, пан, реляция, тракт, фант, фбиляр, хорунжий, шинкарь, шпилька и др.).

Остальные стилистические группы польскоязычных вкраплений малочисленны. К просторечной лексике можно отнести всего четыре полонизма (ср. паршивый, потрафбить, шмат, шматок), к книжной лексике - два полонизма (ср. комплекция, трактовать) и к специальной лексике - два полонизма (ср. литер, шпенек). Классификацию вкраплений польского происхождения по принадлежности к стилю речи иллюстрирует диаграмма ㅇo 4 (см. ниже).

Описывая стилистическую принадлежность полонизмов в лексике русского языка, следует отметить также отнесенность некоторых польскоязычных вкраплений к группе историзмов. Нами созданная база языковых данных отражает всего 13 лексических единиц, обладающих дополнительной стилистической пометой, указывающей на принадлежность данного выражения к разряду историзмов (ср. бричка, вахмистр, гусар, пан, рекрут, ротмистр, таран, улан, фармазон, фбиляр, фбискал, фбузея, хорунжий). Данные выражения относятся в большинстве случаев к нейтральной лексике (ср. бричка, рекрут, ротмистр и др.). Исключение составляют лишь выражения пан, фбигляр и хорунжий со словарной пометой, указывающей на принадлежность к устаревшей лексике. Особого внимания заслуживает также семантика вышеописанной группы полонизмов. ${ }^{3}$

3 Бричка (легкая повозка, крытая или с откидным верхом), вахмистр (в царской России звание и должность унтер-офицера в кавалерии), гусар (в царской армии и ряде европейских стран в XVII-XX вв. - военнослужащий из частей легкой кавалерии, носивших особую форму венгерского образца с галунами), пан (помещик или барин в Польше, на Украине), рекрут (тот, кто принят на военную службу по найму или по повинности), ротмистр (старший офицерский чин в кавалерии 


\section{5 / ВЫВОДЫ}

В настоящей статье продемонстрированы возможности лингвистического анализа вкраплений польского происхождения в лексике русского языка. В ходе отдельных исследований представлены этимологический, семантический и стилистический анализы польскоязычных вкраплений.

С помощью этимологического анализа мы пришли к заключению, что господствующее положение занимает польский язык в роли языка-посредника (85\% от общего количества польскоязычных вкраплений), в роли непосредственного языка-источника выступает польский язык реже (15\% от общего количества польскоязычных вкраплений). Если сосредоточить внимание отдельно на роль польского языка как языка-посредника, таким образом можно выделить первоначальные языки-источники, к числу которых относятся классические языки (латынь и древнегреческий язык), немецкий, французский, итальянский, арабский, венгерский, чешский языки, идиш, голландский язык и группа тюркских языков. Самой многочисленной группой являются полонизмы, относящиеся к греко-латинской основе, представляющие собой половину всех польскоязычных вкраплений. Посредством семантического анализа мы выделили 10 ключевых лексико-семантических групп, в состав которых входят термины экономики и административного аппарата, военные термины, термины гастрономии, культуры, моды, флоры и фауны, медицинские термины, термины науки и транспортного сообщения, ремесленные термины и термины игры (70\% от общего количества польскоязычных вкраплений). Польскоязычные вкрапления, не впадающие тематически в разграниченные семантические группы, мы включили в самостоятельную группу остальных выражений (30\% от общего количества польскоязычных вкраплений). Стилистический анализ осуществлен на основе принадлежности вкраплений польского происхождения к определенному стилю речи. Благодаря данному анализу можно констатировать, что 84\% полонизмов нами созданной базы языковых данных относятся к нейтральной лексике, 16\% полонизмов - польскоязычные вкрапления, принадлежащие к разговорному, устаревшему, просторечному, книжному или специальному пластам лексики русского языка.

В заключение можно подвести итог, что лексические единицы польского происхождения выделяются богатой лексико-семантической разнообразностью и довольно пестрой стилистической принадлежностью. С этимологической точки зрения вкрапления польского происхождения представляют собой многообразный набор лексических единиц, в случае которых польский язык выполняет скорее всего роль языка-посредника по отношению к первоначальным языкам-источникам.

и жандармерии, соответствующий званию капитана в пехоте), таран (осадная машина, предназначенная для разрушения ворот или стен ударами массивного предмета), улан (в царской армии и некоторых других государств - воин легкой кавалерии, вооруженный пикой, саблей и пистолетом), фармазон (приверженец или представитель франкмасонства, т.е. движения, возникшего в XVIII в. в виде закрытой организации), ффиляр (фокусник, шут или акробат), фбискал (в царской России - чиновник, наблюдающий за деятельностью административных учреждений и лиц), фузея (старинное кремневое гладкоствольное ружье), хорунжий (знаменосец или хранитель войскового знамени; также в казачьих войсках царской армии - первое офицерское звание, соответствующее подпоручику и корнету). 


\section{POSSIBILITIES OF LINGUISTIC ANALYSIS OF FOREIGN LANCUAGE INCLUSIONS OF POLISH ORIGIN IN THE VOCABULARY OF THE RUSSIAN LANGUAGE}

SUMMARY The article presents three methods of linguistic analysis of foreign inclusions of Polish origin in the vocabulary of the Russian language. Etymological analysis examines the inclusions of Polish origin by belonging to the Polish language as a source language or as an intermediary language. The dominant position is occupied by the Polish language in the role of an intermediary language, in the role of the direct source language, the Polish language is less frequent. Semantic analysis pays attention to the distribution of Polish-language inclusions in lexical-semantic groups. The article distinguishes lexical and semantic groups, which include the terms of economics and administrative apparatus, military terms, terms of cuisine and dishes, cultural terms, fashion terms, terms of flora and fauna, medical terms, terms of science and transport communications, craft terms and terms games. Stylistic analysis classifies inclusions of Polish origin by belonging to a particular style of speech. Most Polish-language inclusions refer to neutral vocabulary, a small group of polonisms belongs to colloquial, obsolete, vernacular, book or special layers of Russian vocabulary.

\section{ЛИТЕРАТУРА}

I Ахманова О. С., 1966 (2016), Словарь лингвистических терминов, Москва.

I Жеребило Т. В., 2010, Словарь лингвистических терминов, Назрань.

I Климова М. В., 2016, Большой этимологический словарь русского языка, Москва.

I Ожегов С. И. - Шведова Н. Ю., 2017, Толковый словарь русского языка, Москва.

I Плесник Л., 2020, Иноязычные вкрапления польского происхождения в лексике русского языка (общие положения), «Studia Slavica», XXIV/1, c. 67-75.

I Тихонов А. Н. - Хашимов Р. И. (общ. ред.), 2008, Энщиклопедический словарь-справочник лингвистических терминов и понятий. Русский язык, Москва.

I Фасмер М., 1950-1958, Этимологический словарь русского языка, Гейдельберг, https:// lexicography.online/etymology/vasmer/. [цит.: 28.12.2020]

I Черных П. Я., 2009, Историко-этимологический словарь современного русского языка, Москва.

I Шапошников А. К., 2010, Этимологический словарь современного русского языка, Москва.

I Sobol E., 2009, Stownikjezyka polskiego, Warszawa. 

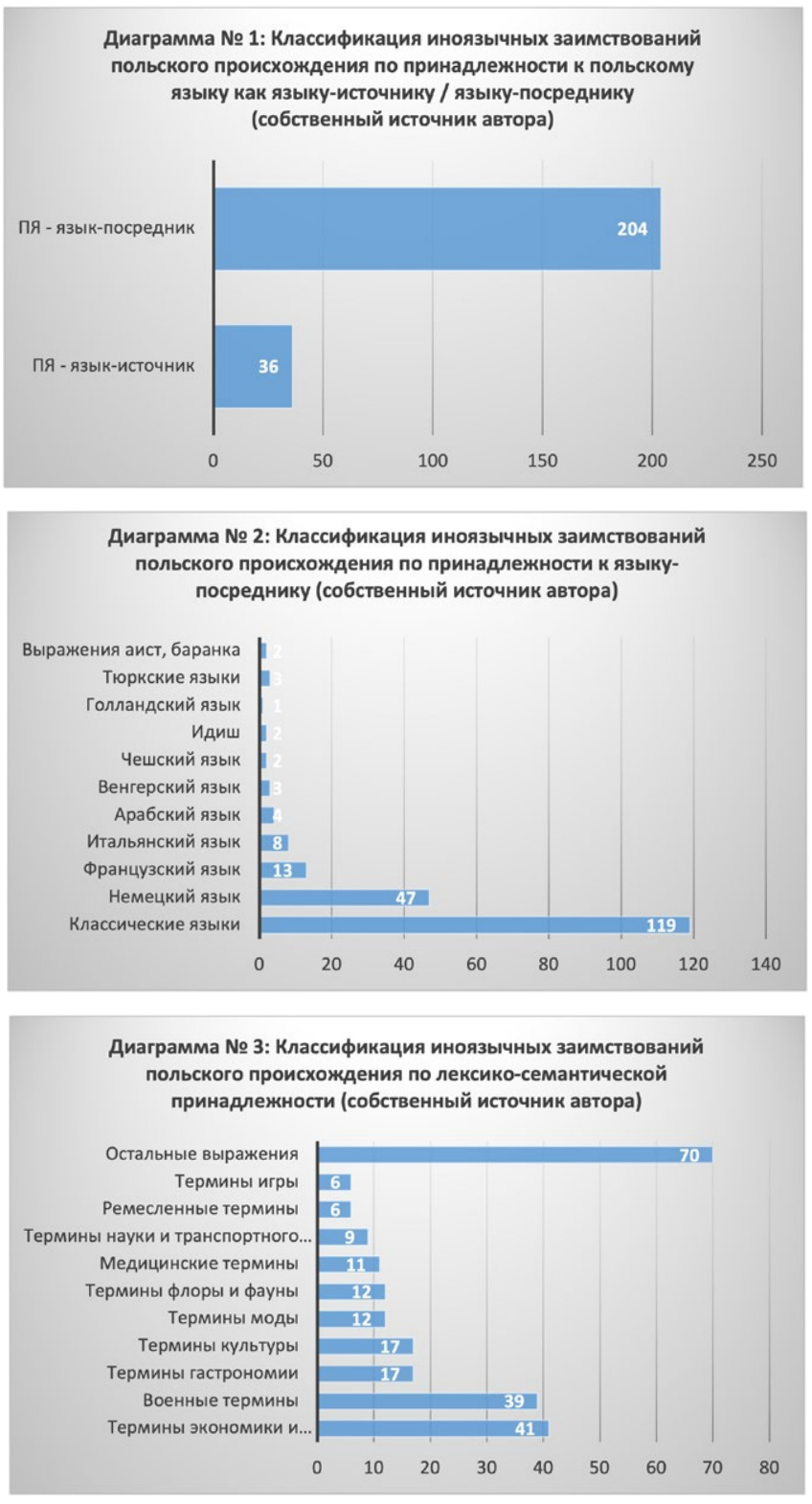

Диаграмма № 4: Классификация иноязычных заимствований польского происхождения по принадлежности к стилю речи (собственный источник автора)

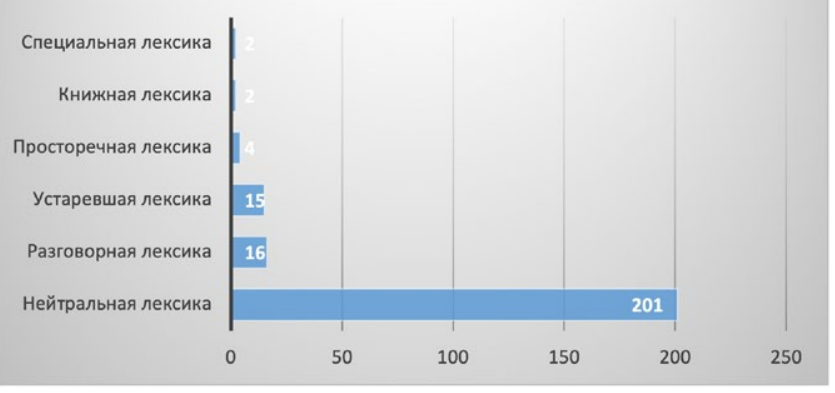

